\title{
LONG-TERM VISION FOR RURAL DEVELOPMENT AND CRITICAL ENABLERS FOR ACHIEVING IT - CASE OF MAZOWIECKIE REGION (POLAND)
}

Pawel CHMIELIŃSKI, European Rural Development Network, Institute of Rural and Agricultural Development Polish Academy of Sciences, Nowy Świat 72, 00-330 Warsaw, Poland, pchmielinski@irwirpan.waw.pl

Barbara WIELICZKO, European Rural Development Network, Institute of Rural and Agricultural Development Polish Academy of Sciences, Nowy Świat 72, 00-330 Warsaw, Poland, bwieliczko@irwirpan.waw.pl (corresponding author)

\begin{abstract}
Rural areas face significant challenges related to climate and demographic changes as well as green transformation of the economy. First step for such a transition is a long-term vision. Within the SHERPA projects multi-actor platforms were created and they discussed the vision for 2040 for their territories. This participatory process included representatives of science, society, and policy. The participants discussed development challenges, vision and enabling factors for achieving the desirable vision. The aim of the paper is to compare the results of the visioning exercise conducted by the Polish platform located in Mazowieckie region with the results of the other ones and the vision prepared by the European Commission. The results show that the characteristics of a desirable future vision are shared throughout the EU and call for vibrant rural communities and rural attractiveness. Improving availability and accessibility of public and private services as well as digitalization and diversification of rural economy accompanied by a sustainable use of natural resources are key elements of vibrance and attractiveness of rural areas. To achieve this vision not only financial support and more efficient public policies are needed but also greater empowerment of local communities is essential.
\end{abstract}

Keywords: rural areas, rural development, long-term vision, participatory approach.

\section{INTRODUCTION}

Rural areas face significant challenges related to climate and demographic changes as well as green transformation of the economy. The specific problems of the rural areas relate to their distance from urban growth centers. However, the dispersion of social and economic activity characterizes all types of rural areas (Stanny et al., 2021) and shapes the challenges related to sustainability transition (Wieliczko et al., 2021). The rural areas in the European Union need to be involved in the implementation of the European Green Deal which is the EU strategy for sustainability transition. Yet so far there has not been prepared o comprehensive strategy of how to support the rural areas in the transition process. It is necessary to identify the threats and opportunities the transition offers to rural areas and rural communities (Pellegrini et al., 2021).

The EU rural areas are diverse and the challenges they face in relation to the transition are of different magnitude and specificity. The European Commission's strategy "Long-term vision for the EU's rural areas - towards stronger, connected, resilient and prosperous rural areas by 2040" (European Commission, 2021) can be seen as a first step to plan an agenda for facilitating the transition of the EU rural areas.

The diversity of rural realities and competing interests of different stakeholder groups call for creating a highly collaborative process of determining the transition pathway and development strategy. Such a process requires engagement and mutual trust of the participants. Imagining the future of rural areas is the first step in this process.

The aim of the study is to compare the results of the discussion on the long-term vision for rural development conducted within the multi-actor platform in Mazowieckie region with the results of such discussions in other such platforms created within the SHERPA project and the long-term vision created by the European Commission.

\section{RESEARCH METHODS}

The study was conducted as part of the Horizon 2020 project entitled Sustainable Hub to Engage into Rural Policies with Actors (SHERPA). It applied a participatory approach to study the needs of rural communities in the EU and to identify policy recommendations. Within the project specially designed multi-actor platforms (MAPs) were created to ensure diversity of participants. These platforms are science-society-policy interfaces. This means that they offer the space for dialogue among different groups of stakeholders. This approach, also known as living labs, offers launching deliberative processes for public decision making which are vital for complex issues (Chwalisz, 2021). Living lab methodology is

Copyright (C) 2021 The Authors. Published by Vytautas Magnus University. This is an open-access article distributed under the terms of the Creative Commons Attribution License (CC BY 4.0), which permits unrestricted use, distribution, and reproduction in any medium, provided the original author and source are credited. 
commonly used in social sciences (Dekker et al., 2020). Living labs are useful tool in to learn about the community needs (Edwards-Schachter et al., 2012) and solve societal challenges (Hossain et al., 2019) as they offer exploration, disruption and open-ended results (Brankaert, den Ouden, 2017). Rural development faced with sustainability transition is a good example of problems that require cooperation and engagement of different stakeholders. Creation of such diverse platforms enables building relations that are empowering participants, allow for learning, coordinating decisions, generate collaboration and co-creation between public sector and citizens (Slätmo et al., 2020). Living lab concept has been acknowledged to be applicable to rural issues. In 2000s the concept of rural living labs was developed focusing on "development of rural areas through involvement of local communities, relevant local stakeholders and stakeholders form different sectors" (Zavratnik et al., 2019). Living labs help in looking for place-based solutions to making rural areas an attractive place to work and live. They also improve engagement of local actors in shaping developmental strategies and policy design. They are seen as a democratic innovation (Asenbaum, Hanusch, 2021) or a way for democratization of public sector innovation (Fuglsang et al., 2021) as well as a governance tool (Schliwa et al., 2015).

The SHERPA MAPs operate under four guiding principles:

- flexible programming;

- co-constructioning policy recommendations;

- multi-level interactions;

- impartiality and transparency (Slätmo et al., 2020).

These principles should help ensure smooth collaboration among the MAP members as the transdisciplinary collaboration process is considered to be one of the biggest challenges of applying the living lab concept (Kalinauskaite et al., 2021).

In the first year 20 regional or national multi-actor platforms were created as well as an EU-level one. The MAPs co-create citizen-led solutions and innovations to address social issues and challenges (Hughes et al. 2019). In the first co-creating cycle, the MAPs were all given a task of creating a desirable vision of rural area in the area covered by their specific MAP. The exercise conducted by MAPs also included identification of challenges in realizing the vision and factors that can act as enablers for achieving the desirable rural areas.

The Polish MAP was created based on the already existing local action group "Zielone Sąsiedztwo" (Green Neighborhood) which operates in rural areas close to Warsaw, Polish capital city. This local action group (LAG) was founded to implement Leader in Brwinów gmina, Milanówek and Podkowa Leśna in the programming period 2007-2013. The members of the LAG include the local policymakers, entrepreneurs, and NGO representatives. To create a MAP the representatives of science were invited. The MAP includes 8 representatives of society, 6 of science and 3 of policy.

The activities of this MAP are designed so that to achieve the following specific objectives:

1. Identification of problems related to rural development.

2. Analysis of necessary policy tools to support rural landscapes and biodiversity.

3. Enumeration of policy instruments needed to create resilient and vibrant rural areas.

\section{RESEARCH RESULTS}

The visioning exercise conducted by the Polish MAP and other SHERPA MAPs was aimed at imaging desirable vision. Thus, the participants were discussing what is needed and welcomed to boost rural attractiveness. Rural attractiveness is understood as the presence of socio-economic and environmental conditions that make a given rural area a place attractive to live and work, which means that there is a good quality of life, good services, and connectivity with nearby urban centers.

The discussions conducted by the members of the MAP in Mazowieckie region evolved around three issues:

- Challenges and opportunities in the next 20 years.

- Desirable future for 2040 .

- Enablers to achieve the vision.

The challenges faced by the rural areas in Mazowieckie region differ in the extend and specific characteristics depending on the location. The peripheral areas of the region, where there is no strong urban growth center are the most deprived ones. Therefore, the region faces challenges that differ in scale and importance depending on the distance from Warsaw or other important urban growth centers. However, the size of Warsaw and its clout leads to significant imbalance in the development of the whole region. The rural areas neighboring Warsaw are well connected with the city while the peripheral areas suffer from lack of transportation connections with Warsaw and other main cities in the region which limits economic activity of their inhabitants as well as their access to education and healthcare.

The challenges in the development of Mazowieckie region relate to all three elements of the sustainable development. The main and the most important challenge for the development of rural areas of the region are demographic changes. All the MAP members agreed that this constituted the key issue for the future of rural areas that needed to be a focal point around which the whole development strategy should be built. The second most important challenge is said to be climate change. No MAP member considered it as "not important" but $30 \%$ stated that the importance of this issue was difficult to assess. The poverty and social inequalities were seen as important by the same share of MAP members as climate change but in this case $10 \%$ of the MAP members saw it as not important issue for the rural areas in the region. Increasing role of digitalization in economy and daily life also met with very homogenous responses. The majority stated it was an important challenge, while the minority did not have a clear opinion on this issue. The fifth listed issue by the 
MAP members were changes in production and diversification of rural economy. In this case the majority did not have a clear opinion on this problem, while the minority considered it an important issue.

The key part of the debate was the desirable vision of rural areas in the perspective of 2040, that is in 20 years. This is a time span that is not too long to be practically unimaginable but given the fact that the discussion was conducted amid the COVID-19 pandemic, the participants were open to think out of the box and be bold in describing their desirable rural vision.

The vision can be summarized to a phrase: "vibrant rural communities". It shows that the society and its wellbeing is put in the center of this vision. The economic and environmental aspects of sustainable development are part of this vision but as preconditions for the human well-being. It is also important to underline that the vision emphasizes the role of community and cooperation among local citizens representing different stakeholder groups.

Environmental issues constitute a vital part of the vision created by the Polish MAP. The vision shows protection of biodiversity and natural resources as part of the desirable future.

The MAP members stated to there are no sufficient resources - financial, political, social, and human - in the region that can be applied to undergo the transition into the desirable future. Support through regional, national and the EU policies is needed to help the rural areas in the process of transition. The rural areas themselves can only offer engagement and commitment to this process. Therefore, as enablers the discussion participants saw all the stakeholders who can in different sectors and at different levels of socio-economic system of rural areas bring about the needed changes in the functioning of rural communities. It was underlined that due to the diversity of development level characterizing rural areas in Mazowieckie, the level of support and conditions under which it is offered should take into account the financial capacity of different communities and types of beneficiaries. Generally, any actions leading to increase in the capacity of rural communities and businesses can be seen as enabler of the transition.

The results of the visioning exercise conducted in the Polish MAP are similar to the ones stemming from all the other MAPs. This can seem a surprising finding given the diversity of rural areas. Yet, despite the differences and specific characteristics the challenges, vision and enablers identified by the different MAPs revolve around the same issues. This also shows that there is a need to act at the EU level as through an EU policy, member states can learn from one another and develop common solutions to the problems present in different parts of the EU.

Most of the other MAPs created in the SHERPA project as challenges identified demographic shift. It covers two phenomena - depopulation and aging. Infrastructure and basic services were also listed. In this case the issues mentioned related to lack of the necessary infrastructure and services, their low accessibility and poor quality. The third key challenge name by the other MAPs related to climate change. The specific problems enumerated in relation to this issue were high temperatures, low annual precipitations, and extreme meteorological phenomena.

The desirable visions described by the other MAPs focused on overcoming the observable current challenges. The majority of MAPs named following themes as vital parts of the vision for their rural areas and communities:

1. Digitalisation and digital technologies highly integrated in the rural economy.

2. A diversified rural economy.

3. A stable and sustainable demographic structure.

4. Environmental conservation, climate adaptation and biodiversity improved.

5. Improved infrastructure, sustainable, innovative mobility models, and access to services.

The enablers identified by the other MAPs were highly diverse in nature and in many cases closely related to the vision for the future of rural areas. Almost $90 \%$ of the MAPs named empowering local actors and communities as well as enhancing multi-level and territorial governance as enablers of reaching the desirable future. This shows that there are not only tangible enablers but also needs related to democracy and good governance that need to be tackled to help rural areas in the process of sustainability transition. The other enablers listed by the majority of the MAPs included:

- Enhancing smart ruralities and digitalization.

- Data and knowledge.

- Funding improved.

- Shift in production and diversification of the rural economy.

There is a strong emphasis on the diversification and digitalization of the rural economy. Less vocal very the voices seeking the opportunities for increasing rural attractiveness via bioeconomy and green transition. Yet, taking care of environment and supporting different forms of entrepreneurship were part of the agenda leading to a desirable future.

\section{DISCUSSION}

The challenges identified by the MAP members are in line with the results of the discussions conducted by other SHERPA MAPs. Moreover, they are similar to the ones named by the EC and the ones listed in the second draft of the Polish CAP strategic plan. This resemblance vividly shows that is not a question of bad local management that there are certain challenges but general policy that is similar irrespective of the location within the EU.

Other studies also bring the problems of rural empowering and increased support to the transition process in line. One of such examples is the participatory process of a foresight study concerning the future of rural areas in the EU conducted European Network for Rural Development (ENRD) let to constructing four scenarios that show different development pathways depending on the strength of different driving forces (Bock, Krzysztofowicz, 2021):

1. Rurbanities scenario - limited coordination between different governance levels, inflow of inhabitants, higher accessibility of public and private services but lower social cohesion and lack of integration of newcomers. 
2. Rural renewal scenario - coordinated green transition progressing faster than in big cities and inflow of new inhabitants willing to get involved in building local communities.

3. Rural connections scenario - digital infrastructure in help of dealing with population decline and the concentration of socio-economic activity in rural hubs.

4. Rural specialisation scenario - rural restructuring partially successful resulting in accelerated depopulation.

These scenarios can be summarized in a two-dimensional matrix shaped by the key determinants of the future of rural areas - rural demography and multi-level governance (Fig. 1).

The results of the discussions within the Polish MAP created a vision of rural areas that is similar to the rural renewal scenario as this is the only desirable scenario characterized by expanding rural areas and networked multilevel governance. Faced with the prospect of sustainability transition, it is of great importance that local communities are involved in the process of deciding how this process is managed.

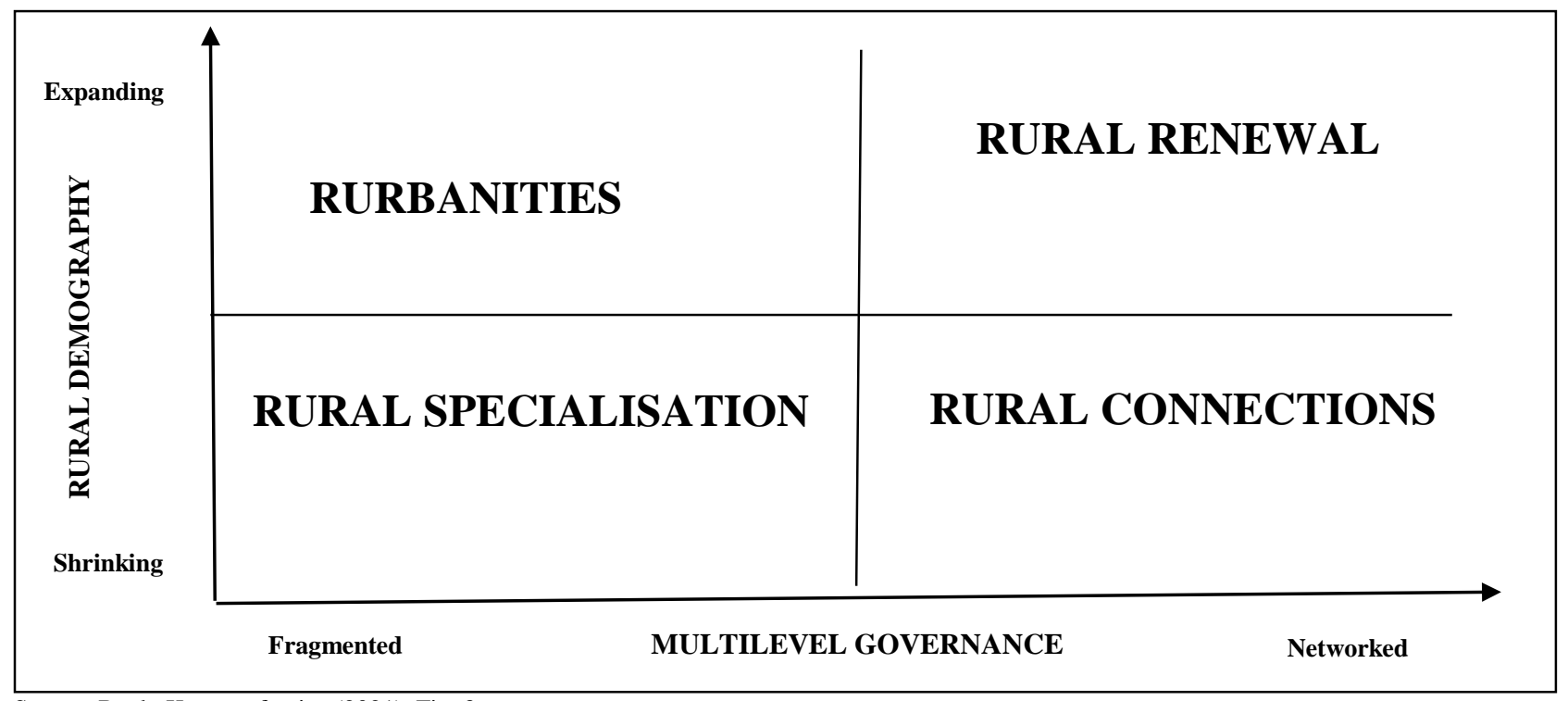

Source: Bock, Krzysztofowicz (2021), Fig. 3.

Figure 1. ENRD's foresight scenario logic

The European Commission's long-term vision repeats the issues present in the discussion of the SHERPA MAPs when it comes to the drivers of the changes for the desirable future for rural areas in the EU (Fig. 2). The EC's vision also mentions "vibrant rural communities" as is the case in the debate of the Polish MAP. This seems to be the key success factor for a just sustainability transition. The transformation of rural inhabitants to rural communities is a challenge as it requires not only empowering the citizens but also requires the citizens to be willing and open for the deliberative processes and taking direct responsibility for their neighborhood.

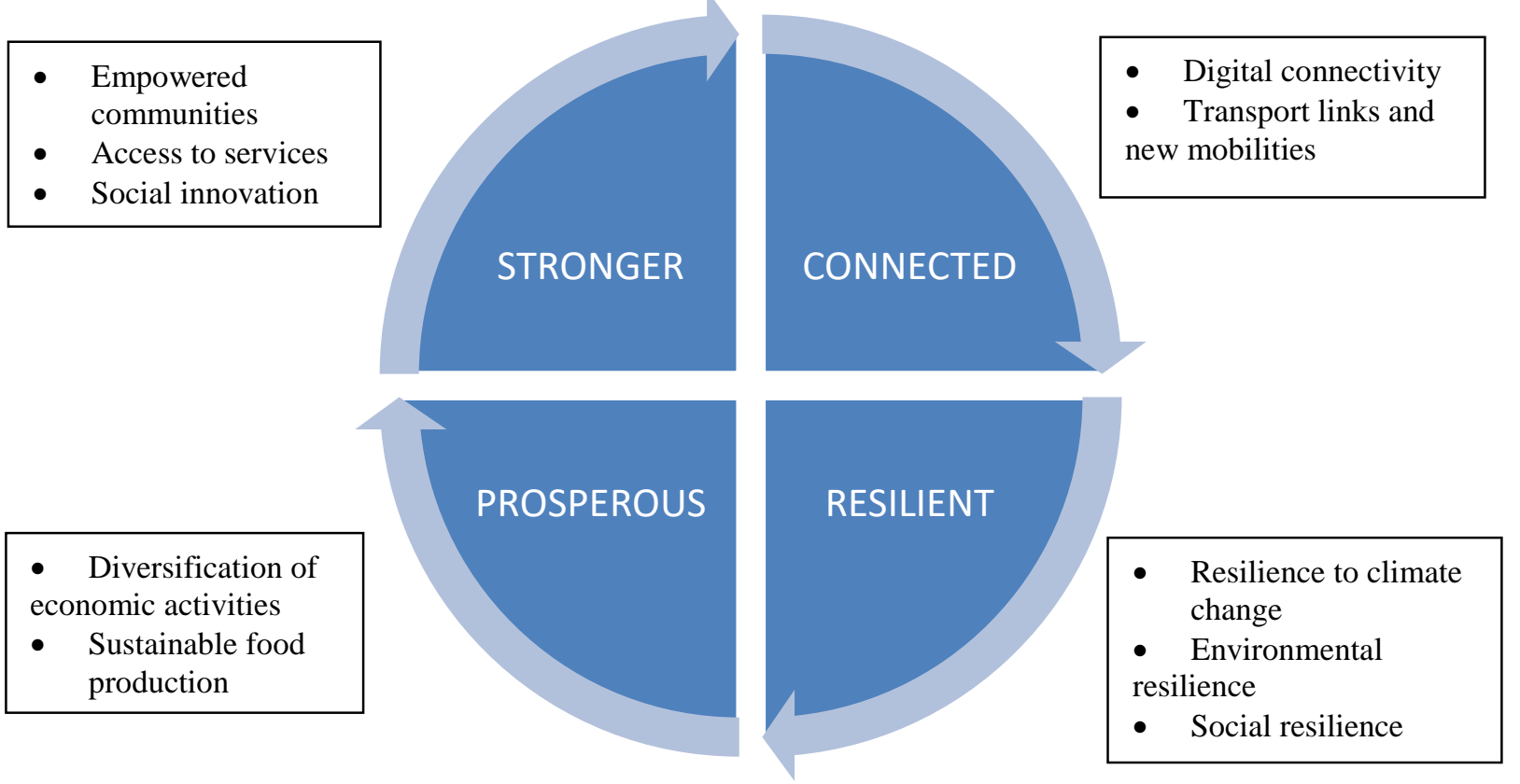

Source: European Commission (2021), Graph 1.

Figure 2. Main drivers shaping the future of rural areas for 2040 and the four complementary areas for action 


\section{CONCLUSIONS}

Multi-actor platforms are an effective tool in determining key needs of local communities. The discussions among actors representing different stakeholder groups help decern the areas of consensus on the vision for development of rural communities and the priorities in improving the attractiveness of rural areas. Such platforms also help in engaging local communities in policy design.

The comparison of the vision for rural areas elaborated by the Polish MAP and the ones prepared by other SHERPA MAPs as well as the vision presented by the EC in its communication present a similar picture. An important part of this picture is the empowerment of local communities. This shows that the provision of services is not sufficient to make the rural areas an attractive place to work and live. Citizens want to have a say in the decision-making process and want to shape the future of their neighborhood. The cooperation of different levels of governance is part of the process of empowerment of the citizens as the local authorities also need empowerment and stronger cooperation with one another and other levels of governance to ensure the best management of available resources.

The commonly expressed problems with provision of public and private services and lacking infrastructure call for rural proofing of public policies and ensuring that they are shaped and implemented in a way that ensures fulfilling territorial justice principles. This is also a way to support a just green transition.

The further step is translating the vision into specific policy measures and providing the necessary funding. Local actors call for more trust from the side of public administration that the beneficiaries of funding use the resources wisely.

\section{REFERENCES}

1. Asenbaum, H., Hanusch, H. 2021. (De)futuring democracy: Labs, playgrounds, and ateliers as democratic innovations. Futures, Vol. 134, 102836. https://doi.org/10.1016/j.futures.2021.102836

2. Bock, A. K., Krzysztofowicz, M. 2021. Scenarios for EU Rural Areas 2040. Contribution to European Commission's long-term vision for rural areas. Publications Office of the European Union, Luxembourg. https://doi.org/10.2760/29388

3. Brankaert, R., den Ouden, E. 2017. The Design-Driven Living Lab: A New Approach to Exploring Solutions to Complex Societal Challenges. Technology Innovation Management Review, Vol. 7, pp. 44-51. https://doi.org/10.22215/timreview/1049

4. Chartier, O., Salle, E., Irvine, K., Kull, M., Miller, D., Nieto, E., Vestergård, L. O., Potters, J., Slätmo, E., Zomer, B., Iadecola, F. 2021. Long-Term Vision for Rural Areas: Contribution from SHERPA science-society-policy platforms. SHERPA Position Paper. https://doi.org/10.5281/zenodo.455744

5. Chwalisz, C. 2021. Innovative Citizen Participation and New Democratic Institutions: Catching the deliberative wave. Presentation available at https://blog.oecd-berlin.de/wp-content/uploads/2021/03/Praesentation_Claudia-Chwalisz-22Feb2021-Catching-thedeliberative-wave.pdf (accessed on 9/9/2021)

6. Dekker, R., Contreras, J. F., Meijer, A. 2020. The Living Lab as a Methodology for Public Administration Research: a Systematic Literature Review of its Applications in the Social Sciences. International Journal of Public Administration, Vol. 43, pp. 12071217. https://doi.org/10.1080/01900692.2019.1668410

7. Edwards-Schachter, M. E., Matti, C. E., Alcántara, E. 2012. Fostering Quality of Life through Social Innovation: A Living Lab Methodology Study Case. Review of Policy Research, Vol. 29, pp. 672-692. https://doi.org/10.1111/j.1541-1338.2012.00588.x

8. European Commission. Communication from the Commission to the European Parliament, the Council, the European Economic and Social Committee and the Committee of the Regions. A long-term Vision for the EU's Rural Areas - Towards Stronger, Connected, Resilient and Prosperous Rural Areas by 2040. COM(2021)345. Available at https://eur-lex.europa.eu/ legalcontent/PL/TXT/?uri=CELEX\%3A52020SC0345\&qid=16290618986

9. Fuglsang, L., Vorre Hansen, A., Mergel, I., Taivalsaari Røhnebæk, M. 2021. Living Labs for Public Sector Innovation: An Integrative Literature Review. Administrative Sciences, Vol. 11, 58. https://doi.org/10.3390/admsci11020058

10. Hossain, M., Leminen, S., Westerlund, M. 2019. A systematic review of living lab literature. Journal of Cleaner Production, Vol. 213, pp. 976-988. https://doi.org/10.1016/j.jclepro.2018.12.257

11. Hughes, H., Foth, M., Mallan, K. 2019. Social living labs for informed learning: A conceptual framework of interprofessional education in community healthcare. Journal of Information Literacy, Vol. 13(2), pp. 112-135. https://doi.org/10.11645/13.2.2641

12. Kalinauskaite, I., Brankaert, R., Lu, Y., Bekker, T., Brombacher, A., Vos, S. 2021. Facing Societal Challenges in Living Labs: Towards a Conceptual Framework to Facilitate Transdisciplinary Collaborations. Sustainability, Vol. 13, 614. https://doi.org/10.3390/su13020614

13. Pellegrini, E., Raggi, M., Viaggi, D., Targetti, S. 2021. Building long-term vision for rural areas through multiactor platforms: a preliminary study in the Emilia-Romagna region. Open Research Europe, Vol. 1, 41. https://doi.org/10.12688/openreseurope.13293.2

14. Schliwa, G., Evans, J., McCormick, K., Voytenko PalganY. 2015. Living Labs and Sustainability Transitions - Assessing the Impact of Urban Experimentation. Paper presented at 'Innovations in Climate Governance', Helsinki, 12-13th March.

15. Slätmo, E, Oliveira e Costa, S., Qvist Eliasen, S. 2020. SHERPA: D5.1 Methods for setting-up of MAPs. https://rural-interfaces. eu/wp-content/uploads/2020/04/SHERPA_D5-1_Methods-setting-up-MAPs.pdf

16. Stanny, M., Komorowski, Ł., Rosner, A. 2021. The Socio-Economic Heterogeneity of Rural Areas: Towards a Rural Typology of Poland. Energies, Vol. 14, 5030. https://doi.org/10.3390/en14165030

17. Wieliczko, B., Kurdyś-Kujawska, A., Floriańczyk, Z. 2021. EU Rural Policy's Capacity to Facilitate a Just Sustainability Transition of the Rural Areas. Energies, Vol. 14, 5050. https://doi.org/10.3390/en14165050

18. Zavratnik, V., Superina, A., Stojmenova Duh, E. 2019. Living Labs for Rural Areas: Contextualization of Living Lab Frameworks, Concepts and Practices. Sustainability, Vol. 11, 3797. https://doi.org/10.3390/su11143797 